\title{
Observation of Climacteric-Like Behavior of Citrus Leaves Using Fluorescence Spectroscopy
}

\author{
Caio B. Wetterich, ${ }^{1}$ Emery C. Lins, ${ }^{1,2}$ José Belasque Jr., ${ }^{3}$ and Luis G. Marcassa ${ }^{1}$ \\ ${ }^{1}$ Instituto de Física de São Carlos, Universidade de São Paulo, 13566-590 São Carlos, SP, Brazil \\ ${ }^{2}$ Centro de Engenharia, Modelagem e Ciências Sociais Aplicadas, Universidade Federal do ABC, 09210-170 Santo André, SP, Brazil \\ ${ }^{3}$ Departamento de Fitopatologia e Nematologia, Universidade de São Paulo, 13418-900 Piracicaba, SP, Brazil
}

Correspondence should be addressed to Luis G. Marcassa; marcassa@ifsc.usp.br

Received 15 April 2014; Accepted 23 May 2014; Published 11 June 2014

Academic Editor: Rodolphe Jaffiol

Copyright (C) 2014 Caio B. Wetterich et al. This is an open access article distributed under the Creative Commons Attribution License, which permits unrestricted use, distribution, and reproduction in any medium, provided the original work is properly cited.

\begin{abstract}
Observation of climacteric-like behavior in citrus leaves depends on the detection of ethylene. However, such detection requires a gas chromatographer and complex sample preparation procedures. In this work, fluorescence spectroscopy was investigated as a diagnostic technique for climacteric-like behavior in citrus leaves. Our results indicate that the chlorophyll fluorescence presents a time evolution consistent with the ethylene evolution. Therefore, fluorescence spectroscopy may be used to observe the climactericlike behavior in citrus leaves.
\end{abstract}

\section{Introduction}

For the last two decades fluorescence spectroscopy of plants has been investigated as a potential technique for diagnostics in vegetation studies [1-3]. The most important aspect of fluorescence spectroscopy is that the technique is nondestructive and nonintrusive to the plant biochemistry, physiology, and ecology. Besides, it is easy and fast to use for many purposes in both the laboratory and field $[4,5]$. Studies using chlorophyll fluorescence emission have been applied successfully to detect mineral deficiencies, water and temperature stress, and pathogens in plants [1, 6-9].

In a paper, our group has used laser induced fluorescence spectroscopy (LIF) to investigate chlorophyll fluorescence as a function of detachment time of the leaves, up to 12 hours [11]. Our results suggested that it was possible to observe the senescence process. This process is associated with a decrease of chlorophyll, RNA, protein, sugar, water contents, and ion unbalance in the leaf. All these factors result in the reduction of the photosystem II activity in the photosynthesis [12], and therefore it must interfere with the chlorophyll fluorescence. In fact, the senescence process has been observed by spectroscopic techniques in a variety of plants [13-16].
A more established technique, to observe the senescence process, consists in measuring ethylene concentration as a function of the detachment time, as it was done by Katz and coworkers [10]. The plant hormone ethylene has profound effects on plant growth and development [17], including the senescence process. The authors have measured the ethylene concentration on detached citrus leaves as a function of time using a gas chromatographer and complex sample preparation procedures [10]. Their results have shown that citrus leaves present climacteric-like behavior.

In this work, we have extended our previous work [11] to investigate chlorophyll fluorescence as a function of detachment time of the leaves. In order to do that, we have used laser induced fluorescence spectroscopy and fluorescence imaging spectroscopy. Our results indicate that it is possible to detect the senescence process using both techniques, with advantages as less time consuming and resources with the fluorescence imaging spectroscopy.

\section{Materials and Methods}

\subsection{Laser Induced Fluorescence Spectroscopy}

2.1.1. Fluorescence Spectroscopy System and LIF Procedure. Our fluorescence spectroscopy system is a portable unit 
(Spectr-Cluster, Cluster Ltd., Moscow, Russia), which was already described in detail in $[11,18,19]$. Briefly, it is composed of (i) one spectrometer, which operates from $350 \mathrm{~nm}$ up to $850 \mathrm{~nm}$; (ii) one Y-shaped fiber, which delivers the laser light through one central fiber and collects the fluorescence from the leaf using six peripheral fibers; and (iii) an excitation source composed of a $10 \mathrm{~mW}$ solid state laser at $532 \mathrm{~nm}$ (second harmonic of Nd:YAG laser). The system also includes an optical filter, which reduces the backscattering signal one thousand times approximately. This allows us to obtain comparable intensity for the backscattering and fluorescence signal.

The spectra were collected from the leaves by placing the optical fiber probe at a fixed distance of $2 \mathrm{~mm}$ above the leaf to avoid any thermal effect [18] and placed about $3 \mathrm{~mm}$ from the midrib. Under these conditions, the optical fiber that collects the fluorescence's sample has a limited solid angle, and the sample size area is about $1 \mathrm{~mm}^{2}$. Each leaf spectrum is an average of 150 fluorescence measurements at the same region in the leaf. The entire procedure took about one minute per leaf.

2.1.2. Leaf Sample Collection. Fluorescence data were collected from 40 mature leaves ( $\sim 8$ months old) from trees of Citrus sinensis (L. Osbeck). They were harvested and stored in the dark at $25^{\circ} \mathrm{C}$ under $\sim 100 \%$ air relative humidity. During the spectroscopy measurements the leaves were removed from its storage for about 5 minutes per day only. The measurements were performed during 14 days after detachment. The samples were prepared as the experiment reported in [10].

\subsection{Fluorescence Imaging Spectroscopy (FIS)}

2.2.1. Fluorescence Imaging Spectroscopy System and FIS Procedure. Our fluorescence imaging spectroscopy system is a homemade portable unit, which is composed of (i) a standard laptop computer; (ii) a monochromatic charged couple device camera (CCD) (model mvBlueFOX120a, Matrix Vision, Germany), which uses a USB communication port; (iii) a filter wheel (model CFW-1-8, Finger Lakes Instrumentation, USA), which holds up to six optical filters and uses a USB communication port; (iv) three passband optical filters at 570 , 690, and $740 \mathrm{~nm}$ (models FB570-10, FB690-10, and FB740-10, Thorlabs, USA); (v) an objective lens; and (vi) high power light emitting diodes (LEDs) at $470 \mathrm{~nm}$ as an excitation source. The CCD and filter wheel are computer controlled by software. This system has a probe area of about $225 \mathrm{~mm}^{2}$ $(15 \times 15 \mathrm{~mm})$. Fluorescence images were collected at 570, 690, and $740 \mathrm{~nm}$. The system is quite portable and can be run on car batteries.

2.2.2. Leaf Sample Collection. In the experiment, the fluorescence data were collected from 10 mature leaves ( 8 months old) from trees of Citrus sinensis (L. Osbeck). We should point out that since the probe area for FIS is larger than LIF, we do not need as many samples as the LIF case for averaging. They were harvested and stored in the dark at $25^{\circ} \mathrm{C}$ under $100 \%$ relative humidity. During the spectroscopy measurements the leaves were removed from its storage for about 5 minutes per day only. The measurements were performed during 14 days after detachment. Again, the samples were prepared as the experiment reported in [10].

2.3. Fluorescence Spectrum Analysis. So far we have used in our optical fiber laser induced fluorescence spectroscopy studies $[11,18,19]$ the figure of merit approach (FM), which is defined as

$$
\mathrm{FM}=\frac{\int_{680}^{712} I(\lambda) d \lambda}{\int_{712}^{750} I(\lambda) d \lambda},
$$

where the FM is the ratio of two integrals of the spectrum $I(\lambda)$ at different wavelength ranges $(680-712 \mathrm{~nm}$ by $712-750 \mathrm{~nm})$. Another ratio that can be used is the red fluorescence to farred fluorescence ratio (RF/FRF), which is defined by the ratio between the chlorophyll fluorescence intensity at $685 \mathrm{~nm}$ and the fluorescence intensity at $735 \mathrm{~nm}$.

Since the fluorescence imaging spectroscopy system uses optical filters, it does not have the spectral resolution to obtain FM. Nevertheless, the filters have a bandwidth of $10 \mathrm{~nm}$, which may be interpreted as an integral over the transmission curve of the filter. Therefore, the images at $570 \mathrm{~nm}\left(\mathrm{IM}_{1}\right)$, at $690 \mathrm{~nm}\left(\mathrm{IM}_{2}\right)$, and at $740 \mathrm{~nm}\left(\mathrm{IM}_{2}\right)$ may be defined, respectively, as

$$
\begin{aligned}
& \mathrm{IM}_{1}=\int_{\text {filter } 570 \mathrm{~nm}} I(\lambda) d \lambda, \\
& \mathrm{IM}_{2}=\int_{\text {filter } 690 \mathrm{~nm}} I(\lambda) d \lambda, \\
& \mathrm{IM}_{3}=\int_{\text {filter } 740 \mathrm{~nm}} I(\lambda) d \lambda .
\end{aligned}
$$

And finally, we can define the two figures of merit image as

$$
\mathrm{FMI}_{1}=\frac{\mathrm{IM}_{2}}{\mathrm{IM}_{3}}, \quad \mathrm{FMI}_{2}=\frac{\mathrm{IM}_{1}}{\mathrm{IM}_{2}} .
$$

In fact, each image is composed of a large amount of pixels. And in order to obtain a single parameter per image, we have averaged all the pixels. Since the FIS sample size is larger than the LIF sample size, it is not surprise that we need less samples for this average. It is important to point out that the leaf fluorescence at $570 \mathrm{~nm}$ has been associated with carotenoids $[13,15]$.

\section{Results and Discussion}

In Figure 1, we present FM ratio (Figure 1(a)) and RF/FRF ratio (Figure 1(b)) as a function of time after detachment for the LIF experiment. Each point is an average over all leaves, and the error bars were taken as the variance of all measurements. We can observe that the overall behavior of the RF/FRF ratio is similar to the FM; however, the FM presents small error bars and maximum values smaller than 


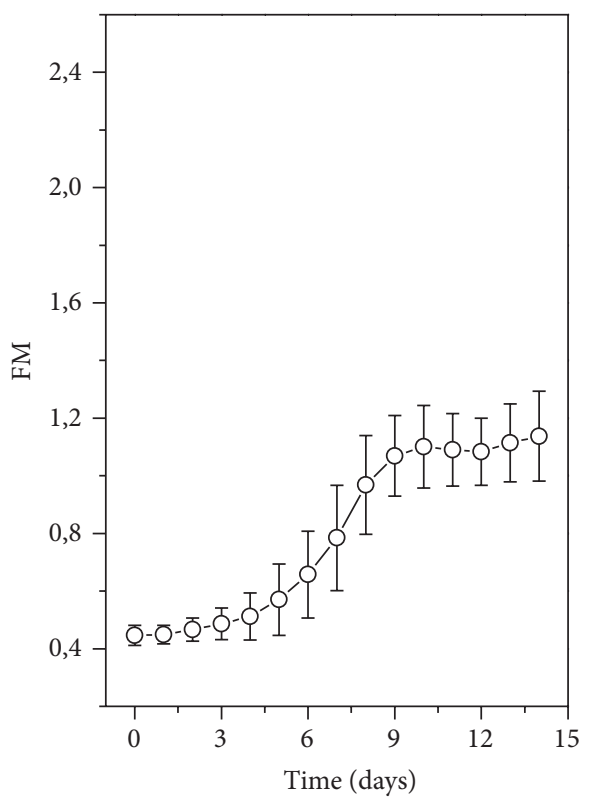

(a)

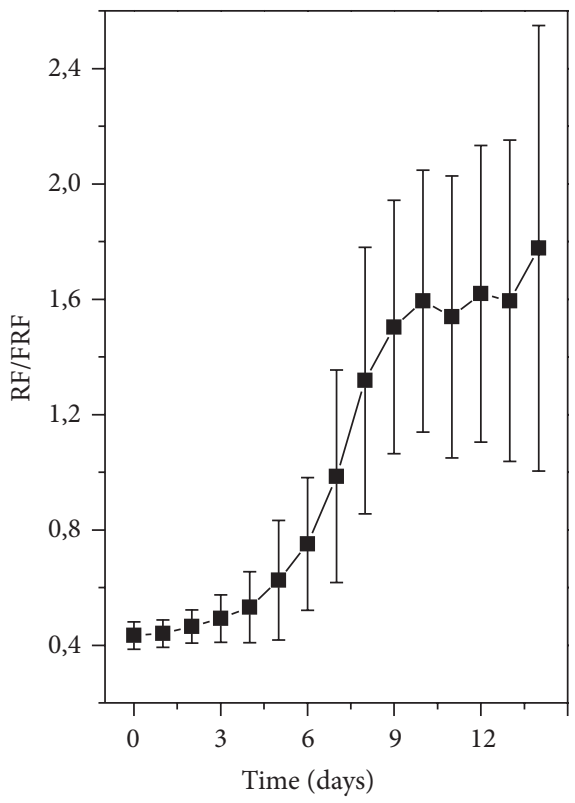

(b)

FiguRE 1: (a) Figure of merit (FM) and (b) RF/FRF ratio as a function of time after detachment for the LIF experiment.

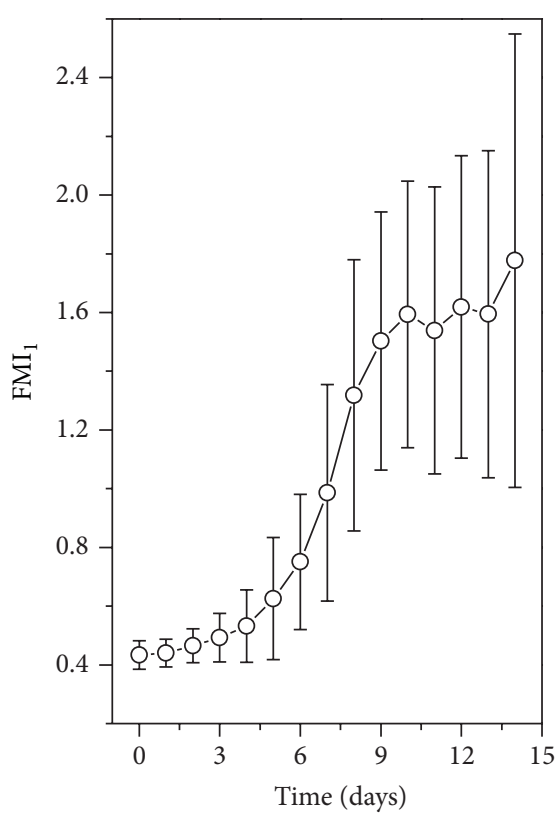

(a)

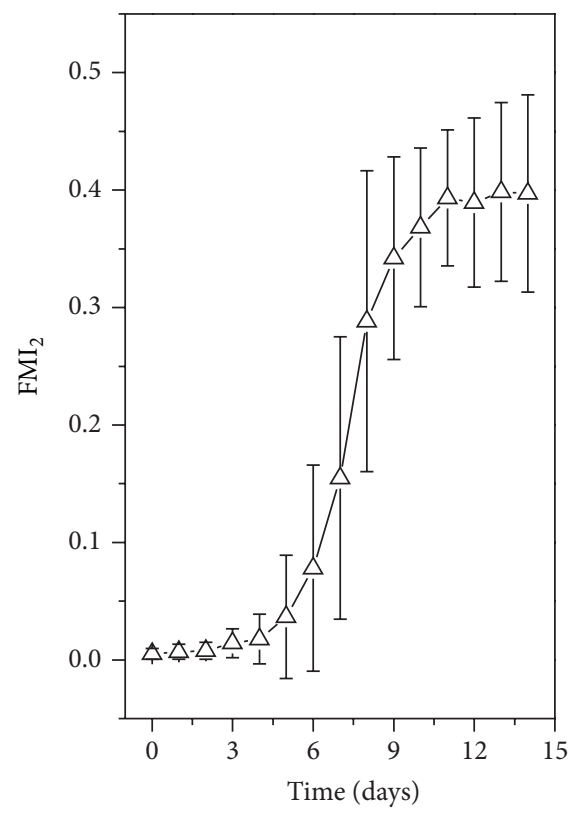

(b)

FIGURE 2: (a) $\mathrm{FMI}_{1}$ and (b) $\mathrm{FMI}_{2}$ ratio as a function of time after detachment for the FIS experiment.

RF/FRF in the last six days of evaluation. As pointed out in our previous work [18], we believe that the integration reduces the effect of peak shifts, and therefore it reduces the variance of the results. We should also notice that the values of RF/FRF ratio are larger than the FM, since FM's denominator (1) is larger than the RF/FRF denominator.

In Figure 2, we present $\mathrm{FMI}_{1}$ (Figure 2(a)) and $\mathrm{FMI}_{2}$ (Figure 2(b)) as a function of time after detachment for the FIS experiment. Each point is an average over all leaves and pixels. The error bars were taken as the variance of all measurements. As an example, the $\mathrm{FMI}_{1}$ images as a function of time are shown in Figure 3. Although the FIS sample size is $15 \times 15 \mathrm{~mm}$, we have used here a smaller sample $(8 \times 8 \mathrm{~mm})$, as shown in Figure 3, to avoid the midrib region. We can observe that qualitative and quantitative behavior of the $\mathrm{FMI}_{1}$ is equal to the RF/FRF. In fact, this was expected since the optical filter 


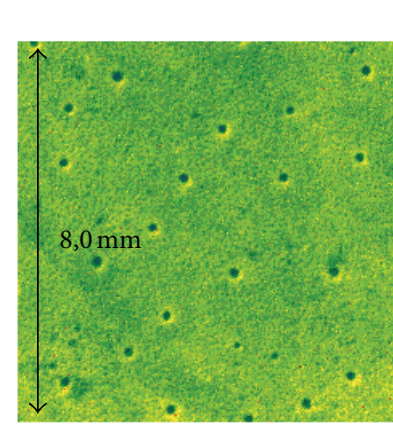

(a)

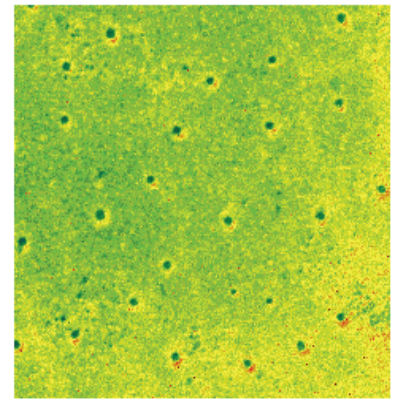

(d)

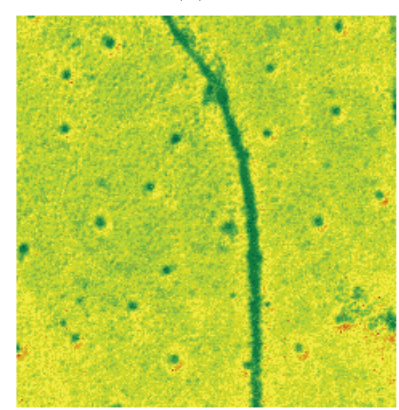

(g)

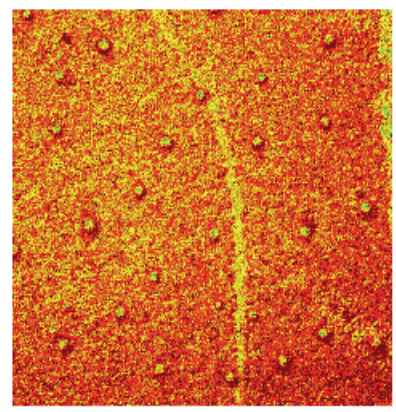

(j)

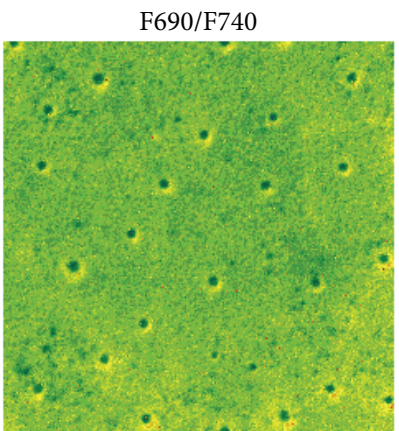

(b)

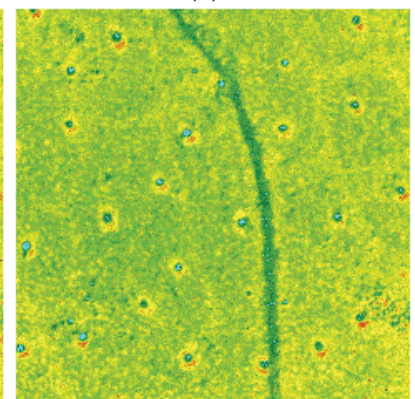

(e)

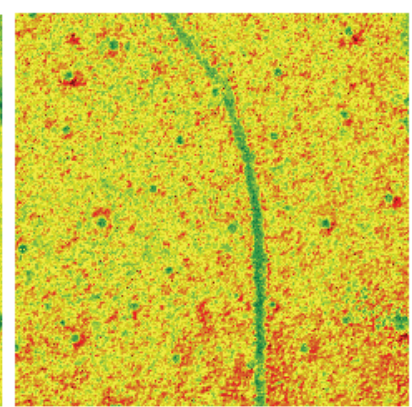

(h)

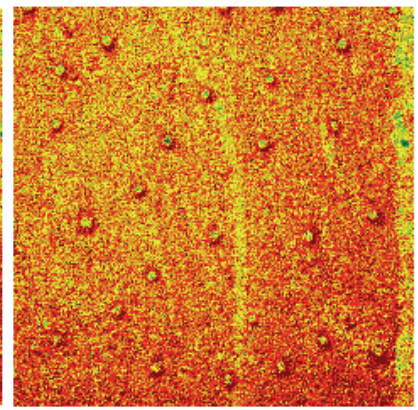

(k)

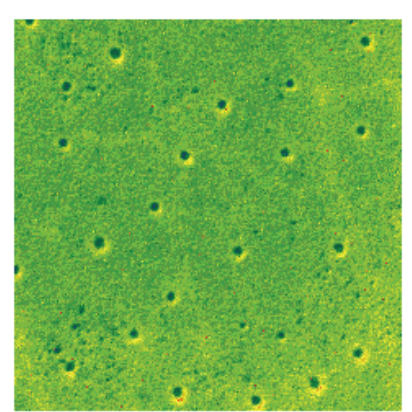

(c)

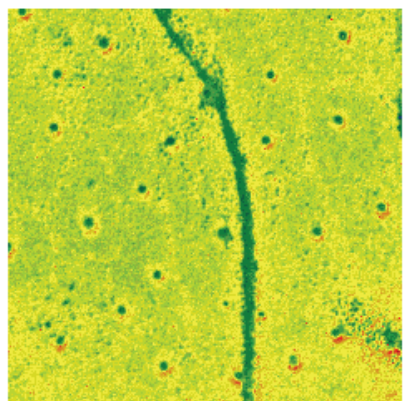

(f)

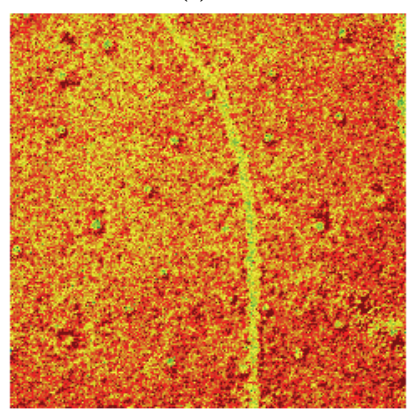

(i)

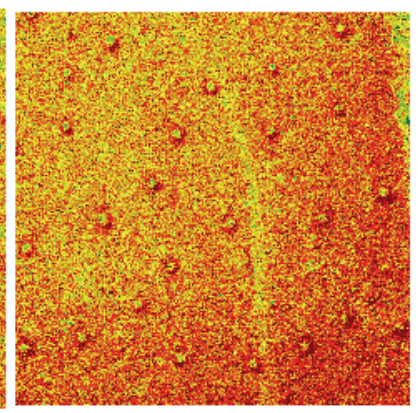

(1)

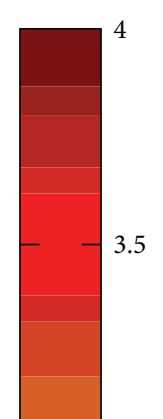

.5
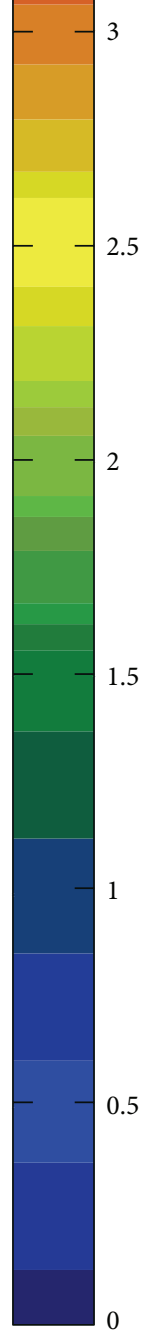

1.5

0.5

FiguRE 3: FMI image as a function of detachment time (a) 0 days; (b) 1 day; (c) 2 days; (d) 3 days; (e) 4 days; (f) 5 days; (g) 6 days; (h) 7 days; (i) 8 days; (j) 9 days; (k) 10 days; (l) 11 days.

is quite narrow and $\mathrm{FMI}_{1}$ is obtained by basically the same operation as the RF/FRF ratio.

We should point out that the increase as a function of time, observed for $\mathrm{FM}, \mathrm{RF} / \mathrm{FRF}$, and $\mathrm{FMI}_{1}$ ratios, was expected, since such ratios have an inverse relationship with the chlorophyll content in the leaf $[1,2,13,20,21]$. And it is well known that the senescence process is associated with a decrease of chlorophyll $[12,13]$. The increase observed for the $\mathrm{FMI}_{2}$ ratio shows a qualitative agreement with the results obtained by Gruszecki and coworkers [13], which has been assigned to the singlet-singlet energy transfer from the carotenoids to chlorophyll.

It seems that all parameters considered at the present work have similar time dependence. All parameters are basically constant up to 3 days after the leaf detachment. Then, they increase almost linearly up to 9 days and reach 
TABLE 1: Fitting parameters for all fluorescence ratios.

\begin{tabular}{lcc}
\hline Ratio & $t_{0}$ (days) & $\Delta t$ (days) \\
\hline FM & $6.7 \pm 0.1$ & $1.2 \pm 0.1$ \\
RF/FRF & $7.2 \pm 0.2$ & $1.3 \pm 0.1$ \\
FMI $_{1}$ & $7.2 \pm 0.2$ & $1.3 \pm 0.1$ \\
FMI $_{2}$ & $7.3 \pm 0.1$ & $1.00 \pm 0.05$ \\
\hline
\end{tabular}

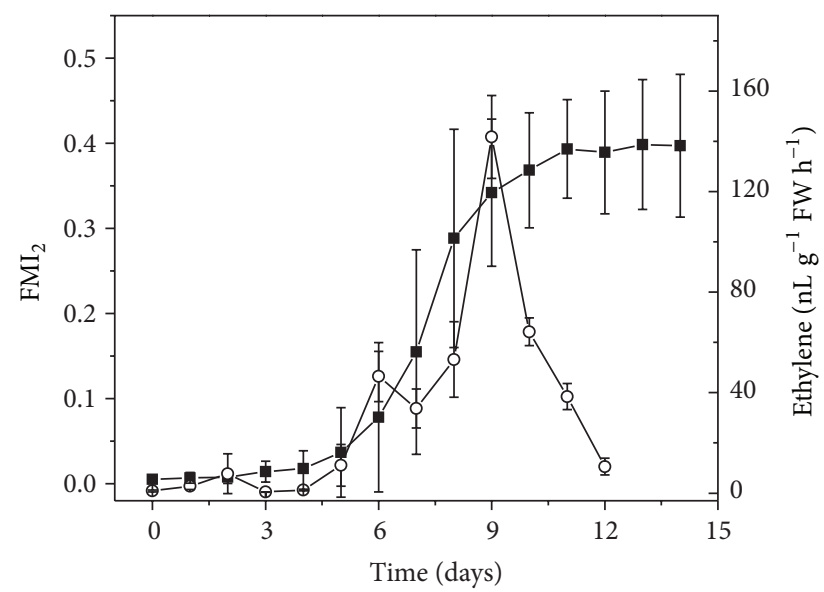

FIGURE 4: $\mathrm{FMI}_{2}$ time evolution (black square-left axis) and the ethylene time evolution (white circle — right axis) from [10].

saturation. At 9 days, such parameters have reached in average up to $90 \%$ of the saturation value. Due to the phenomenological time dependence of all ratios, we have fitted them with the following function:

$$
y=\frac{A_{1}-A_{2}}{1+e^{\left(t-t_{0}\right) / \Delta t}}+A_{2}
$$

where $A_{1}$ and $A_{2}$ are the initial and final values, which will depend on the studied ratio. The other two fitting parameters are $t_{0}$, the time necessary for the ratio to reach the $\left(A_{1}-A_{2}\right) / 2$ value, and $\Delta t$, which is the time interval where the ratios behave linearly. In Table 1, we show the fitting parameters for all ratios. Clearly, all ratios have similar fitting parameters, although $\mathrm{FMI}_{2}$ presents the sharpest time evolution, since its $\Delta t$ is the smallest.

In Figure 4, we compare the $\mathrm{FMI}_{2}$ time evolution with the ethylene time evolution from [10]. We have chosen the $\mathrm{FMI}_{2}$ parameter for such comparison, but any other parameter would present the same behavior. The peak at the ethylene time evolution from [10] happens around 9 days. Therefore, the ethylene peak happens when the fluorescence parameters have reached $90 \%$ of the saturation value of any fluorescence parameter. In Figure 5, we compare the $\mathrm{FMI}_{2}$ derivative time evolution with the ethylene time evolution from [10]. Again, we should stress that all the fluorescence parameters present similar derivatives. One may notice that the $\mathrm{FMI}_{2}$ derivative peaks between 48 and 24 hours, preceding therefore ethylene peak and the climacteric-like behavior. The possibility of predicting the ethylene peak in advance may be a useful ability in storage chambers and packing house, since ethylene is associated with fruit ripening process.

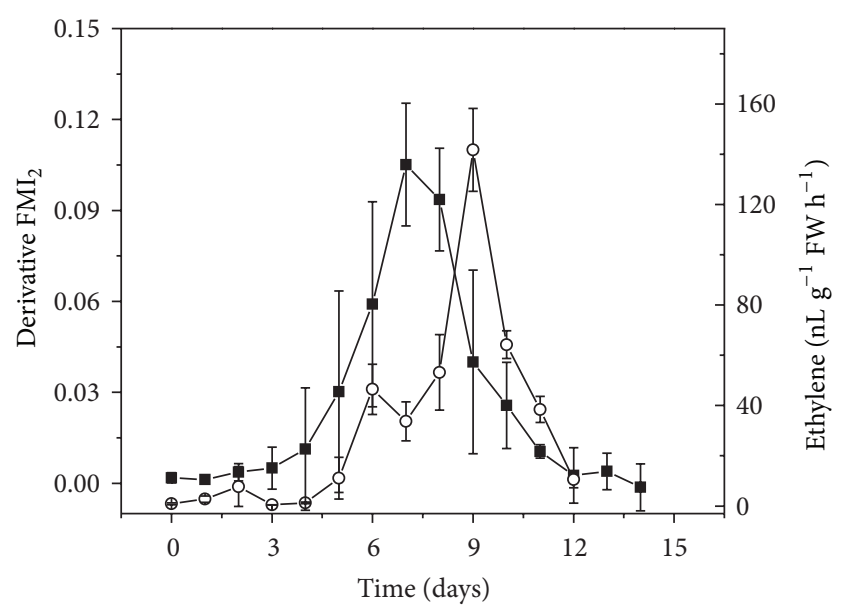

FIGURE 5: $\mathrm{FMI}_{2}$ derivative time evolution (black square-left axis) and the ethylene time evolution (white circle-right axis) from [10].

\section{Conclusion}

In summary, we have demonstrated that LIF and FIS can be used as a detection tool for climacteric-like behavior in citrus leaves through fluorescence spectroscopy. The diagnostic procedure is very simple for both techniques. However, we should point out that FIS is simpler since it does require fewer samples than LIF. We believe that the fluorescence parameters time evolution precedes the ethylene time evolution for both techniques. Besides, there is no doubt that the fluorescence technique is much simpler than a gas chromatographer. Although the experiments were carried out in a laboratory, both systems have been operated in the field as well $[11,18,19]$. For large scale applications, like ethylene time monitoring in storage chambers and packing houses, FSI may be more convenient since it can process larger samples faster. In conclusion, spectroscopy may be a powerful tool to detect the physiological state of plants because monochromatic light interacts with molecules in a highly specific and selective way.

\section{Conflict of Interests}

The authors declare that there is no conflict of interests regarding the publication of this paper.

\section{Acknowledgments}

This work is supported by Grants 2010/16536-9 and 2011/22275-6, the São Paulo Research Foundation (FAPESP), and CNPq. The authors also thank the authors of [10] by providing us the ethylene data shown in Figures 4 and 5.

\section{References}

[1] Z. G. Cerovic, G. Samson, F. Morales, N. Tremblay, and I. Moya, "Ultraviolet-induced fluorescence for plant monitoring: present state and prospects," Agronomie, vol. 19, pp. 543-578, 1999. 
[2] C. Buschmann and H. K. Lichtenthaler, "Principles and characteristics of multi-colour fluorescence imaging of plants," Journal of Plant Physiology, vol. 152, no. 2-3, pp. 297-314, 1998.

[3] H. K. Lichtenthaler and J. A. Miehé, "Fluorescence imaging as a diagnostic tool for plant stress," Trends in Plant Science, vol. 2, no. 8, pp. 316-320, 1997.

[4] Govindjee, "Sixty-three years since Kautsky-Chlorophyll a fluorescence," Australian Journal of Plant Physiology, vol. 22, pp. 131-160, 1995.

[5] G. H. Krause and E. Weis, "Chlorophyll fluorescence and photosynthesis: the basics," Annual Review of Plant Physiology and Plant Molecular Biology, vol. 42, no. 1, pp. 313-349, 1991.

[6] A. F. Theisen, "Fluorescent changes in a drying maple leaf observed in the visible and near-infrared," in Applications of Chlorophyll Fluorescence in Photosynthesis Research, Stress Physiology, Hydrobiology and Remote Sensing, H. K. Lichtenthaler, Ed., vol. 197, Kluwer Academic Plublisher, Dordrecht, The Netherlands, 1988.

[7] M. Broglia, "Blue-green laser-induced fluorescence from intact leaves: actinic light sensitivity and subcellular origins," Applied Optics, vol. 32, no. 3, pp. 334-338, 1993.

[8] E. W. Chappelle, F. M. Wood Jr., J. E. McMurtrey, and W. Wayne Newcomb, "Laser-induced fluorescence of green plants. 1: a technique for the remote detection of plant stress and species differentiation," Applied Optics, vol. 23, no. 1, pp. 134-138, 1984.

[9] J. Cervantes-Martínez, R. Flores-Hernández, B. RodríguezGaray, and F. Santacruz-Ruvalcaba, "Detection of bacterial infection of agave plants by laser-induced fluorescence," Applied Optics, vol. 41, no. 13, pp. 2541-2545, 2002.

[10] E. Katz, J. Riov, D. Weiss, and E. E. Goldschmidt, "The climacteric-like behaviour of young, mature and wounded citrus leaves," Journal of Experimental Botany, vol. 56, no. 415, pp. 1359-1367, 2005.

[11] L. G. Marcassa, M. C. G. Gasparoto, J. Belasque Jr., E. C. Lins, F. Dias Nunes, and V. S. Bagnato, "Fluorescence spectroscopy applied to orange trees," Laser Physics, vol. 16, no. 5, pp. 884888, 2006.

[12] D. W. Lawlor, Photosynthesis, BIOS Scientific Publishers Ltd, New York, NY, USA, 3rd edition, 2001.

[13] W. I. Gruszecki, K. Veeranjaneyulu, B. Zelent, and R. M. Leblanc, "Energy transfer process during senescence: fluorescence and photoacoustic studies of intact pea leaves," Biochimica et Biophysica Acta, vol. 1056, no. 2, pp. 173-180, 1991.

[14] J. A. Gamon and J. S. Surfus, "Assessing leaf pigment content and activity with a reflectometer," New Phytologist, vol. 143, no. 1, pp. 105-117, 1999.

[15] W. W. Adams III, K. Winter, U. Schreiber, and P. Schramel, "Photosynthesis and chlorophyll fluorescence characteristics in relationship to changes in pigment and element composition of leaves of Platanus occidentalis L. during autumnal leaf senescence," Plant Physiology, vol. 93, no. 4, pp. 1184-1190, 1990.

[16] Q. Lu, C. Lu, J. Zhang, and T. Kuang, "Photosynthesis and chlorophyll a fluorescence during flag leaf senescence of fieldgrown wheat plants," Journal of Plant Physiology, vol. 159, no. 11, pp. 1173-1178, 2002.

[17] F. B. Abeles, P. W. Morgan, and M. E. Saltveit Jr., Ethylene in Plant Biology, Academic Press, San Diego, Calif, USA, 1992.

[18] J. Belasque, M. C. G. Gasparoto, and L. G. Marcassa, "Detection of mechanical and disease stresses in citrus plants by fluorescence spectroscopy," Applied Optics, vol. 47, no. 11, pp. 19221926, 2008.
[19] E. C. Lins, J. Belasque Jr., and L. G. Marcassa, "Optical fiber laser induced fluorescence spectroscopy as a citrus canker diagnostic," Applied Optics, vol. 49, no. 4, pp. 663-667, 2010.

[20] A. A. Gitelson, C. Buschmann, and H. K. Lichtenthaler, "Leaf chlorophyll fluorescence corrected for re-absorption by means of absorption and reflectance measurements," Journal of Plant Physiology, vol. 152, no. 2-3, pp. 283-296, 1998.

[21] A. A. Gitelson, C. Buschmann, and H. K. Lichtenthaler, "The chlorophyll fluorescence ratio $F_{735} / F_{700}$ as an accurate measure of the chlorophyll content in plants," Remote Sensing of Environment, vol. 69, no. 3, pp. 296-302, 1999. 

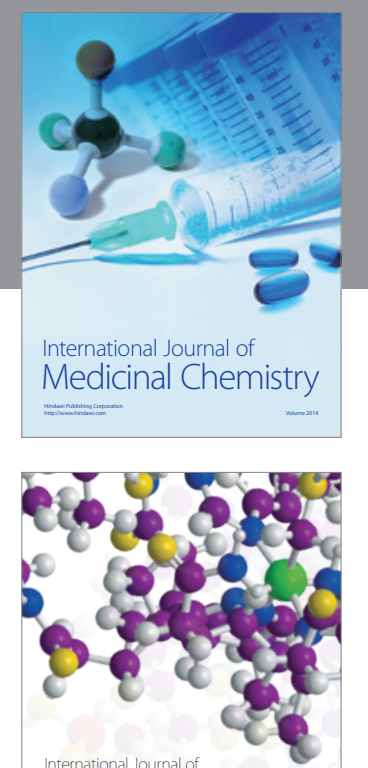

\section{Carbohydrate} Chemistry

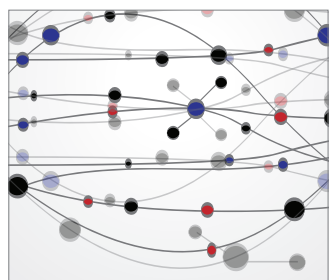

The Scientific World Journal
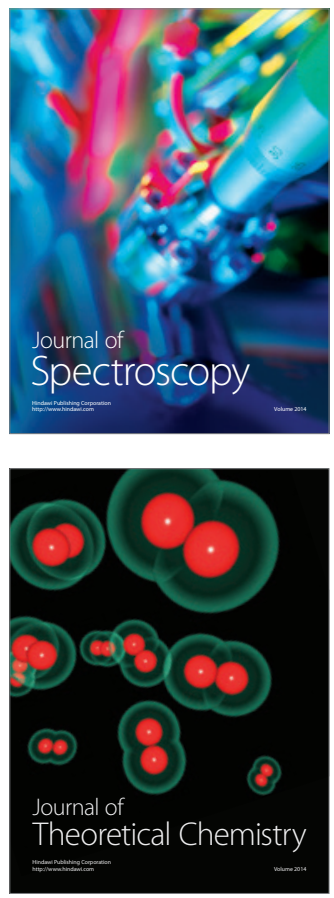
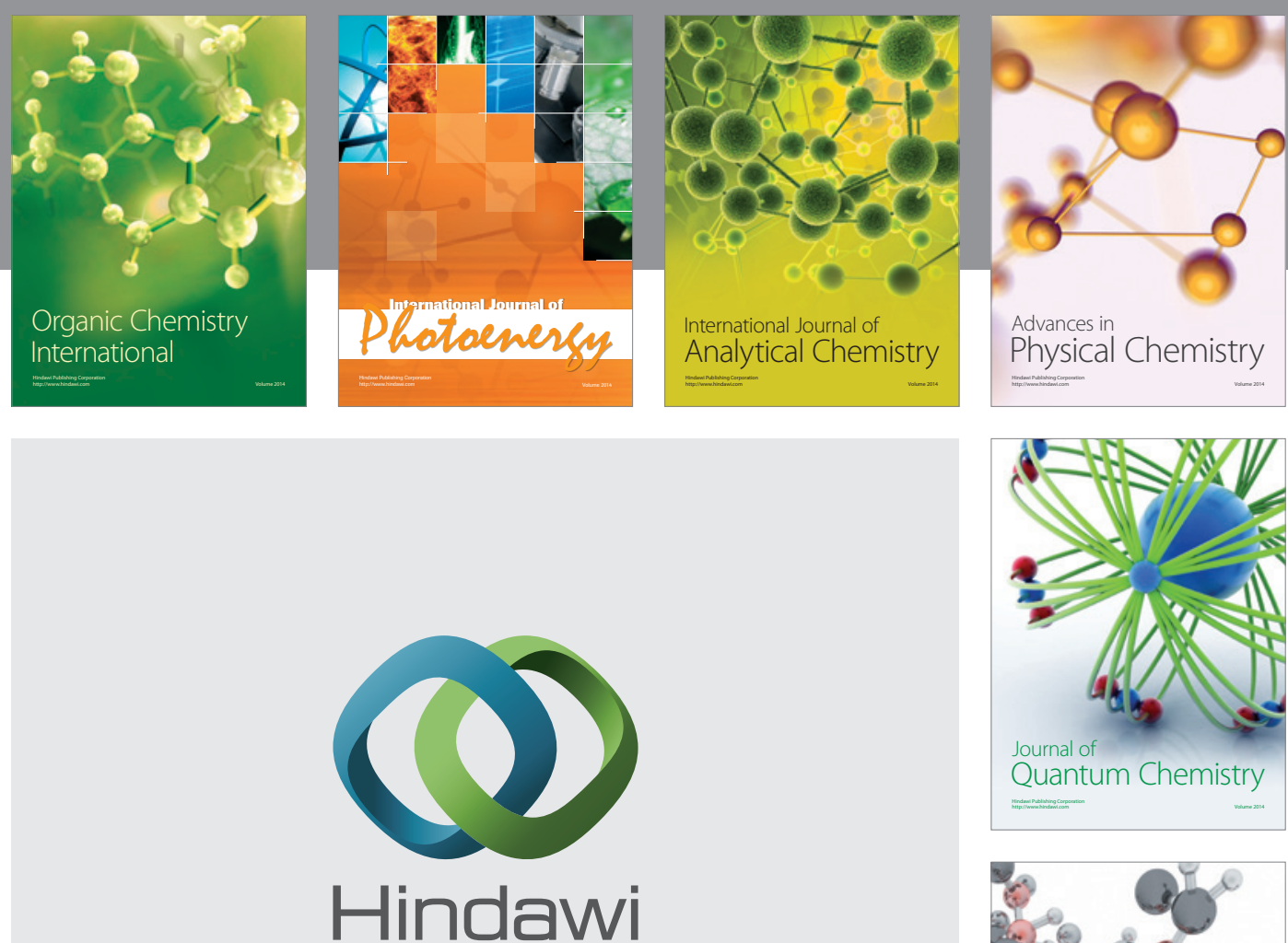

Submit your manuscripts at

http://www.hindawi.com

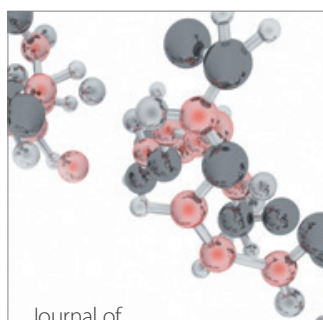

Analytical Methods

in Chemistry

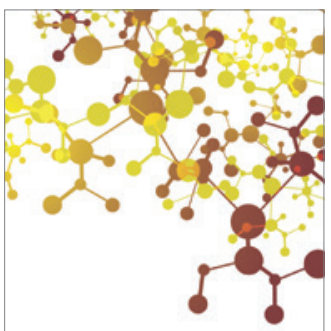

Journal of

Applied Chemistry

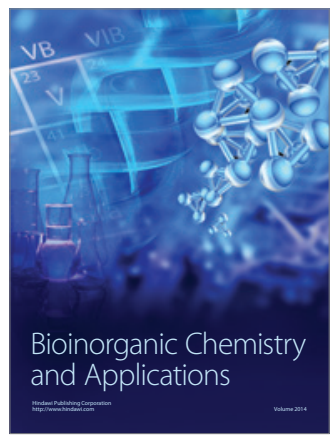

Inorganic Chemistry
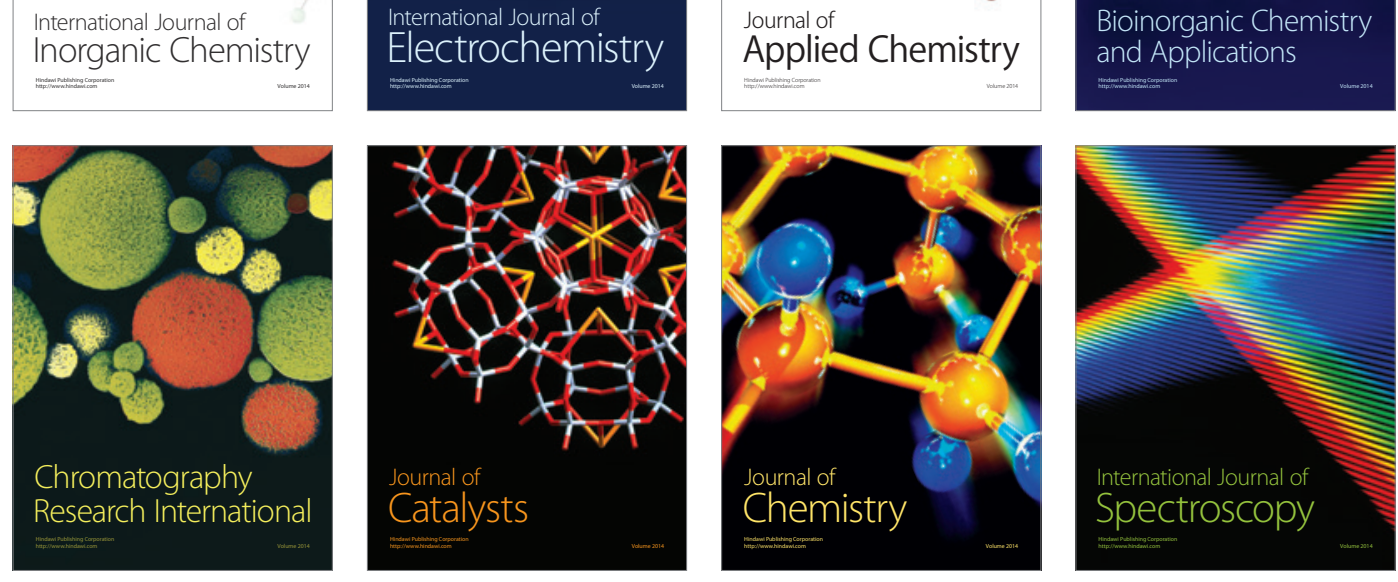